\begin{tabular}{|c|c|}
\hline Title & Plant constituents affecting food selection by sika deer \\
\hline Author(s) & A getsuma, Naoki; A getsuma Y anagihara, Y oshimi; T akafumi, Hino; Nakaji, Tatsuro \\
\hline Citation & $\begin{array}{l}\text { Journal of wildlife management, 83(3), 669-678 } \\
\text { https://doi.org/10.1002/wmg.21615 }\end{array}$ \\
\hline Issue Date & 2019-03-21 \\
\hline Doc URL & http:/hdl.handle.net/2115/77753 \\
\hline Rights & 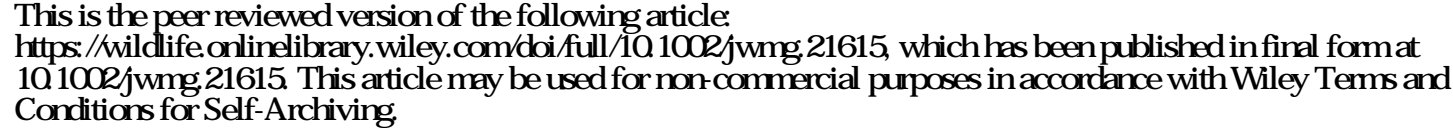 \\
\hline Tyре & article (author version) \\
\hline File Information & plant_c.pdf \\
\hline
\end{tabular}

Instructions for use 


\title{
Plant Constituents Affecting Food Selection by Sika Deer
}

\author{
Naoki Agetsuma ${ }^{1}$, Yoshimi Agetsuma-Yanagihara, Hino Takafumi, Tatsuro Nakaji
}

\begin{abstract}
We directly observed the feeding behaviors of Yaku sika deer (Cervus nippon yakushimae), the smallest subspecies of Japanese sika deer, by following 6 wild, habituated, and individually identifiable animals in a natural warm-temperate forest on the island of Yakushima, southern Japan, 2005-2006. Deer fed on various plant species and parts but predominantly on the fallen leaves, fruits, seeds, and flowers of woody plants (ca. $82 \%$ of food items) at 59 natural feeding plots. We analyzed 8 key plant constituents of eaten and uneaten items at the feeding plots, and examined the effects of each constituent on food selection by multivariate and univariate generalized linear mixed models. The multivariate analysis, which evaluated the effect of each plant constituent on food selection by controlling influences of the other constituents in the food items, showed that deer selected food items with higher contents of crude fat, crude protein, and total phenolics but with lower contents of lignin and condensed tannin from the available items at the feeding plots. Neither soluble nor structural carbohydrate, nor ash content affected selection of food items. It may be advantageous for these small ungulates with shorter gastrointestinal tracts to select foods that are relatively rich in fat because of the higher energy content of fat compared with carbohydrates. Furthermore, it appears that non-tannin phenolics may have beneficial functions in this species. The univariate analyses showed different effects of crude protein and structural carbohydrate on food selection compared to those derived from the multivariate analysis. We demonstrate that accounting for influences of other plant constituents by using multivariate analyses is important to ensure that any effects of individual plant constituents are not overlooked or overstated.
\end{abstract}

KEY WORDS behavioral observation, Cervus nippon yakushimae, crude fat, crude protein, feeding plot, lignin, multivariate analysis, total phenolics, warm temperate forest.

\footnotetext{
${ }^{1}$ Tomakomai Experimental Forest, Field Science Center for Northern Biosphere, Hokkaido University, Takaoka, Tomakomai, Hokkaido 053-0035, Japan. E-mail: agetsuma@fsc.hokudai.ac.jp
} 
Food selection is a fundamental component of ecological interactions between animals and their environment (Hanley 1997) and influences the habitat use and activity patterns of a range of species (e.g., Japanese macaque [Macaca fuscata], Agetsuma 1995, Agetsuma and Noma 1995; grizzly bear [Ursus arctos], Munro et al. 2006; platypus [Ornithorhynchus anatinus], McLachlan-Troup et al. 2010). In studies on food selection by herbivores, energy and protein are the 2 main forage components because both are essential for maintaining body condition, growth, and reproduction, and yet have been suggested to have the most limited availability for wild animals (Nakagawa 1989, Robbins 1993, Hanley 1997). By contrast, structural carbohydrates, lignin, and plant secondary metabolites have negative effects on food selection because they may reduce digestion rates (Alm et al. 2002, Hochman and Kotler 2006, Hanya et al. 2007, Ulappa et al. 2014). Consequently, some studies have defined food quality based on these key plant constituents without confirming the actual effects of these constituents on food selection by the subject animals (Robbins 1993, Berteaux et al. 1998, Johnstone et al. 2002, Moser et al. 2006, Simard et al. 2008).

Many studies on ungulates have examined the effects of these key constituents on the selection of food items from available options (Tixier et al. 1997, Forsyth et al. 2002, Dostaler et al. 2011, Zweifel-Schielly et al. 2012). The results, however, have not always been as expected (Dostaler et al. 2011). For example, researchers reported that ungulates selected food items with less soluble carbohydrates (Vourc'h et al. 2002, Ceacero et al. 2012) and protein (Berteaux et al. 1998, Vourc'h et al. 2002, Verheyden-Tixier et al. 2008, Ceacero et al. 2012, Zweifel-Schielly et al. 2012), and more structural carbohydrates (such as neutral detergent fiber and cellulose; Vourc'h et al. 2002, Verheyden-Tixier et al. 2008, Ceacero et al. 2012), lignin (Vourc'h et al. 2002, Verheyden-Tixier et al. 2008), and plant secondary metabolites (Tixier et al. 1997, Verheyden-Tixier et al. 2008, Zweifel-Schielly et al. 2012), though this can vary with some conditions such as season or individual. It has been argued that these inconsistencies are related to characteristics of the ungulate digestive system (VerheydenTixier et al. 2008) or the influence of varying seasons (Van der Wal et al. 2000, ZweifelSchielly et al. 2012). It is also possible, however, that these inconsistencies result from methodological issues in food selection studies on ungulates in natural habitats and in captivity.

Food plants of ungulates in the wild have mainly been identified by analyzing the contents of rumens and feces, or by observing browsing marks left by ungulates on plants. However, these approaches all have weaknesses. It is generally difficult to identify plant parts to species in the rumen or feces, resulting in food items being combined into broad categories, such as grasses, forbs, and browse (Moser et al. 2006, Zweifel-Schielly et al. 2012), and the amounts of individual plant constituents may differ greatly among the species even within each of these categories. Fecal analyses are also confounded because digestibility can vary between food types (Verheyden-Tixier et al. 2008, Wam and Hjeljord 2010). Furthermore, it is sometimes uncertain whether the locations in which the ungulates were shot to obtain the 
rumens are coincident with their foraging grounds and the environmental availability of food items eaten (Bee et al. 2011). Browsing marks are difficult to consistently quantify across various food types (Wam and Hjeljord 2010), and if ungulates frequently feed on forest litter, such as fallen leaves and fruits (Gayot et al. 2004, Soumya et al. 2010, Agetsuma et al. 2011, Tsuji et al. 2015), there are often no traces of consumption. Some of these difficulties can be resolved by conducting feeding experiments in captivity and semi-captivity. For example, cafeteria tests can control the key constituents of the available food items, sometimes using artificial pellet foods, and measure the amount of each food item that is eaten (Berteaux et al. 1998, Alm et al. 2002, Hochman and Kotler 2006, Dostaler et al. 2011). Even when animals in captivity have been presented with natural plants, however, the number of food items and number of combinations that are presented to them are often less (Deguchi et al. 2001, Dostaler et al. 2011, Huang et al. 2012) compared with availability at natural feeding situations.

Direct observation of the feeding behavior of wild animals in their natural habitats has the potential to avoid most of the methodological problems that are inherent in indirect dietary analyses and food selection experiments in captivity as discussed above, provided the plant species, plant parts, and even the condition of food plants that are eaten can be sufficiently identified (Agetsuma et al. 2011). Direct observation also provides information of potential foods that are available to specific animals when they select food items. However, the feeding behavior of wild ungulates is often difficult to observe and consequently, few such studies have been conducted (Hjeljord et al. 1990, Agetsuma et al. 2011).

The analytical methods used can also affect the evaluation of the relationship between plant constituents and food selection. Food items consist of a variety of constituents, all of which have the potential to affect food selection and in potentially interacting ways. Many studies, however, have evaluated the effects of individual constituents without considering the influences of other constituents (Vourc'h et al. 2002, Verheyden-Tixier et al. 2008, ZweifelSchielly et al. 2012), which may limit inferences derived from such studies. Analytical methods that consider co-variation between plant constituents should improve our understanding of the actual effect of each constituent on food selection (e.g., multivariate modeling procedures; Tixier et al. 1997, Deguchi et al. 2001).

Factor analysis (FA) or principal component analysis (PCA; Forsyth et al. 2005, Dostaler et al. 2011) can be useful for characterizing groups of food items in relation to food selection but cannot be used to detect the effects of each constituent individually because the factors are expressed as mixtures of constituents, which makes evaluation of the relative importance of individual plant constituents difficult. Moreover, some constituents showing positive correlations with the first axis may have negative correlations with the second axis (Vangilder et al. 1982), which would make explanation of the effect of the constituents confusing. Geometric frameworks may be suitable methods for visualizing and conceptualizing the importance of plant constituents on food selection (Raubenheimer et al. 2015, Felton et al. 
2016). This method is somewhat limited because it cannot assess $>3$ constituents simultaneously or control the influences of other constituents in the food items.

In this study, we focused on plant constituents that affect selection of food items by wild ungulates under natural feeding situations. To avoid the methodological issues of dietary and data analyses inherent in previous studies on food selection, we directly observed wild deer selecting food items from other available items in a natural forest and analyzed the effects of key plant constituents in these items on the food selection using a multivariate analysis. We predicted that crude fat, crude protein, and soluble carbohydrate would have positive effects, and structural carbohydrate, lignin, total phenolics, and condensed tannin would have negative effects on food selection by wild deer. In addition, we examined differences in the results of multivariate and univariate analyses to better understand the effect of analytical methods on studies of food selection.

\section{STUDY AREA}

The subject of this study was Yaku sika deer (Cervus nippon yakushimae), one of the smallest subspecies of Japanese sika deer (Whitehead 1993), which is endemic to the islands of Yakushima and nearby Kuchino-Erabujima, southern Japan. Mean body mass of adult ( $\geq 4$ years old) females and males in the study area were $21 \mathrm{~kg}$ (range $=18-25 \mathrm{~kg}, n=18)$ and $28 \mathrm{~kg}$ (range $=24-37, n=15$ ), respectively (N. Agetsuma, Hokkaido University, unpublished data). Density of deer in the study area was high (100-110 individual $/ \mathrm{km}^{2}$; Koda et al. 2011), likely because of the absence of natural predators of Yaku sika deer on the island since the last Ice Age (Environment Agency 1984) and the high productivity of the evergreen broad-leaved forest. The deer typically formed small groups that included several individuals (Agetsuma et al. 2003), with groups of $>10$ individuals temporarily gathering on occasion. Mean annual home range size (expressed as a 90\% fixed kernel) was 12 ha (range $=7-17, n=4$ ) for adult females and 36 ha (range $=4-78, n=4$ ) for adult males (Agetsuma et al. 2005). Hunting was prohibited in the study area, but feral domestic dogs occasionally killed deer. Other mediumsized mammals that inhabited the study area were Yakushima macaques (M.f. yakui) and raccoon dogs (Nyctereutes procyonoides), which were introduced to the island around 1990 (Tsujino and Agetsuma-Yanagihara 2006).

We established our study area in a lowland warm temperate evergreen broad-leaved forest on the western coast (ca. $1 \mathrm{~km} \times 10 \mathrm{~km}, 10-250 \mathrm{~m}$ above sea level) of the island of Yakushima $\left(30^{\circ} \mathrm{N}, 130^{\circ} \mathrm{E} ; 503 \mathrm{~km}^{2}\right)$ in 2005 and 2006 . Most parts of the study area were within a natural World Heritage site and Special Protection Area of Yakushima National Park, where settlements or cultivation were not allowed and logging was prohibited. The annual mean temperature was approximately $21^{\circ} \mathrm{C}$, which corresponds with the transition between the subtropical and warm temperate zone (Tagawa 1994) and annual precipitation was approximately 2,600mm (Tagawa 1980). We defined the annual seasons in this study area as spring (Apr-Jun), summer (Jul-Sep), autumn (Oct-Dec), and winter (Jan-Mar). The 
vegetation in the study area mainly consisted of approximately 45 -year-old secondary forest and some primary forest, and was dominated by evergreen species of Fagaceae, Myrsinaceae, and Lauraceae. Subtropical plants such as banyan trees (Ficus superba var. japonica, $F$. microcarpa), charcoal-tree (Trema orientalis), and large spiny tree fern (Cyathea spinulosa) were also present. The plant species diversity of the forest was relatively high (Tagawa 1980), but forest floor vegetation was poorly developed in the study area and tended to be dominated by several fern species where present. The area also included small isolated plantations of Japanese cedar (Cryptomeria japonica) and small areas of grassland along roadsides, the seashore, and on mudslides (Agetsuma et al. 2011, Agetsuma and Agetsuma-Yanagihara 2018).

\section{METHODS}

\section{Behavioral Observation}

We captured wild deer for individual identification from 2001 to 2005 using animal capture and handling protocols that had been reviewed and permitted by the Ministry of the Environment, Government of Japan (KanKyushu [number 031119001], Kikenryoho [number 10-0004]). We immobilized the deer with an intramuscular injection of xylazine and ketamine delivered by air dart gun. We marked the deer with radio-collars (ca. 130 g; model M2950; ATS, Isanti, MN, USA), the weights of which were $<1.0 \%$ of their body mass, and then administered the antagonist tolazoline to the deer.

We started to observe the behavior of the deer $>2$ months after capture. We observed wild deer behavior intermittently between January 2005 and September 2006, with observation periods occurring in each season. We chose 3 adult females and 3 adult males as focal animals in this study (Table S1, available online in Supporting Information), which could be identified by their collars or natural marks. Although these individuals were living in the wild, they were habituated to researchers because wildlife researchers have conducted long-term behavioral observations of monkeys (e.g., Maruhashi 1981, Agetsuma 1995) and deer (e.g., Agetsuma et al. 2003, 2011) in the study area. Subject female Q had 1 female fawn and 2 or 3 daughters of 1-4 years old during the study period, whereas female Yon had 1 male in each of 2005 and 2006; these young were also habituated to the presence of researchers. Female San did not have any young (she gave birth in 2005, but the fawn died). The adult males were solitary but temporarily stayed with other males and females. The home ranges of 5 of the 6 focal animals were overlapping or adjacent to each other, with the home range of male Teto disjunct but still within the study area.

We planned to observe at least 3 individuals including both sexes for more than 40 hours in each season of each year. On each observation day, we followed focal animals mainly during daylight hours at 2-10m (Fig. 1). They foraged in areas with trees and rocks sometimes within complex topography, and they frequently changed body postures and directions, which made continuous, uninterrupted observation of detailed movements of deer mouths almost 


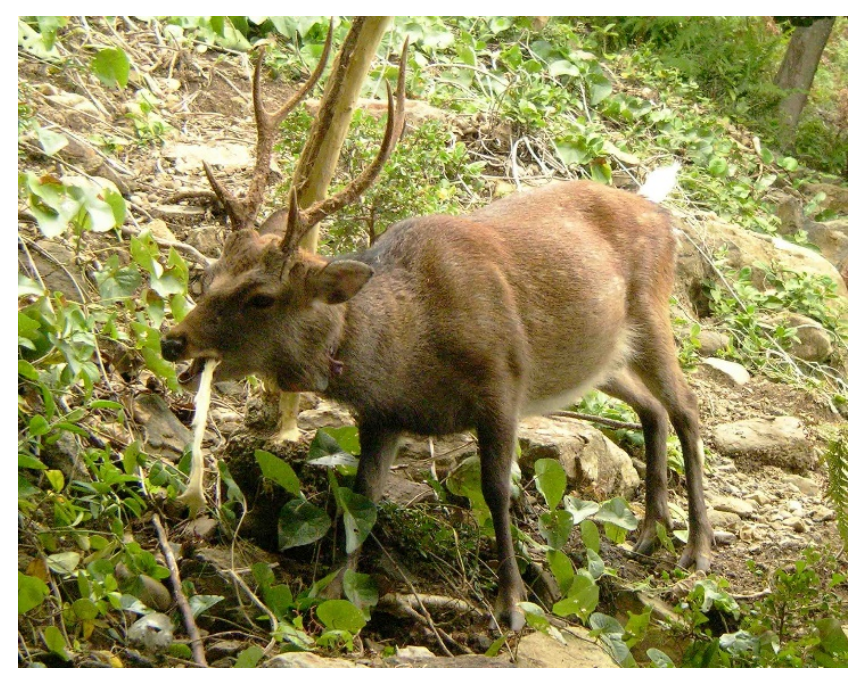

Figure 1

One of the focal animals for behavioral observation of wild Yaku sika deer (Teto) in a warm temperate evergreen broad-leaved forest on Yakushima, southern Japan. He was feeding on living bark of Makino's mallow (Hibiscus makinoi) in summer 2006. impossible. Therefore, we used a scan sampling method (Altmann 1974) that recorded their first behavior observed every 2 minutes for as long as possible (Agetsuma et al. 2011). We classified animal behaviors during scans as moving, feeding, resting, and other. When the deer were feeding, we recorded which plant parts were eaten: mature leaves, new leaves, buds, bark, flowers, fallen mature leaves, fallen new leaves, fallen bracts, fallen flowers, fallen fruits, fallen seeds, or rotten bark. We further categorized the condition of fallen leaves of woody plants into fresh green leaves, red- or yellowtinged leaves, or dry brown leaves. We identified food items eaten by the focal deer to species, or the highest taxonomic level in the case of fallen items.

\section{Plant Sampling and Constituent Analyses}

We defined the plant species and parts that were eaten by the focal deer as food items. Deer were often recorded in multiple scans feeding on the same food item within an area of the forest floor with a radius of several meters before moving to another location. Therefore, we defined a feeding plot as an area with a radius of $5 \mathrm{~m}$ within which we recorded $\geq 3$ scans of feeding on the same food item, which implied feeding on that item for $\geq 6$ minutes on average. We marked the locations of these feeding plots during, or shortly after behavioral observations (total 59 feeding plots; Table S1). In some cases, we observed that deer fed on 2 food items simultaneously (e.g., green leaves and fruits attached to the same fallen branch) in $\geq 3$ scans, or 2 food items each in $\geq 3$ scans within a single feeding plot at a time (plots 24,27 , and 38; Table S1). In these cases, we recorded the area as a feeding plot for each of the 2 food items. In 2 cases, focal deer used the same place for feeding on different food items on different observation days within a season, so we treated these as independent observations (plots 6 and 16).

We established a 5-m $\times 5-\mathrm{m}$ quadrat in the center of each feeding plot. Within each quadrat, we measured the area of cover of the green parts of each plant species $\left(\geq 0.09 \mathrm{~m}^{2}\right.$ cover) from $0-1.5 \mathrm{~m}$ above the ground (the approximate height range that the deer can reach). For feeding plots that included bark as a food item, we also measured the surface area of the bark $\leq 1.5 \mathrm{~m}$ above ground. We summed the cover for all plant parts at each feeding plot, and 
then calculated the cover for each plant part of each species as a percentage of the total. We classified any plant parts of each species that contributed $\geq 10 \%$ of the cover at each feeding plot as available items.

We took samples of each of the available items and the food items that were fed on by the focal deer within $30 \mathrm{~m}$ from each feeding plot. In 24 cases, we could not collect sufficient samples of specific items for plant constituent analysis in the feeding plots in which they were observed, so we subsequently collected the food item or a close congener in the same observation periods from a nearby area (Table S1). For the analysis of fat content of fallen fruit of red bayberry (Myrica rubra; plot 41), we obtained samples during the same season of the following year.

We also sampled forest litter (any fallen plant parts) at each feeding plot where present. Among the sampled litters, we sorted the most abundant species and parts as available items at that feeding plot. In all cases, these were brown fallen leaves of woody species. We were unable to determine the most abundant species distinctly in the litter at feeding plot 54, so we used a mixture of the fallen leaves as a sample for that feeding plot.

We dried all samples by a heated-air dryer at $40^{\circ} \mathrm{C}$ to avoid decreasing the extraction efficiency of polyphenols (Constantinides and Fownes 1994, Joint FAO/IAEA Division of Nuclear Techniques in Food and Agriculture 2000) within several hours of sampling, then triturated and stored samples at room temperature for plant constituent analyses. We analyzed 8 key constituents in each plant item: crude fat, crude protein, soluble carbohydrate, structural carbohydrate (hemicellulose and cellulose), lignin, total phenolics, insoluble condensed tannin, and ash contents (presented as \% of dry matter). Because deer appeared consistently to spit out the shells of fallen seeds (acorns) of Japanese stone oak (Lithocarpus edulis) and Japanese willowleaf oak (Quercus salicina) when they fed on those items, we analyzed only the albumens of the seeds of these species. We measured the total nitrogen content by the combustion method using a carbon-nitrogen analyzer (Sumigraph NC-900; Sumika Chemical Analysis Service, Tokyo, Japan) and then multiplied the result by 6.25 to calculate the crude protein content (Van Soest et al. 1991, Robbins 1993). We determined the contents of soluble carbohydrate, structural carbohydrate, total phenolics, condensed tannin, and lignin without correction for the ash fraction as described by Osono and Takeda (2005) with some modifications. We weighed and shook dried sample powder (ca. $25 \mathrm{mg}$ ) with $12 \mathrm{ml} 50 \%$ (volume basis) methanol at $70^{\circ} \mathrm{C}$ for 1 hour in a polypropylene test tube. After centrifugation at $12,000 \mathrm{G}$ for 10 minutes, we analyzed the extract solution for soluble carbohydrate, total phenolics, and condensed tannin. We measured the soluble carbohydrate content as D-glucose equivalent using the phenol-sulfuric acid method (Dubois et al. 1956). We also measured the total phenolics content as gallic acid equivalent using the Folin-Ciocalteu method, and analyzed the condensed tannin content using the butanol-hydrochloric acid method and expressed in cyanidin chloride equivalents (Osono and Takeda 2005).

We rinsed the residue after the first 50\% methanol treatment with 50\% methanol and 
centrifuged again. We repeated this rinsing process 3 times. Thereafter, we dried the residue and mixed with $0.75 \mathrm{ml}$ of $72 \%$ (volume basis) sulfuric acid solution at room temperature for 2 hours. We diluted the mixture to $2.5 \%$ sulfuric acid with distilled water and autoclaved at $121^{\circ} \mathrm{C}$ for 1 hour. After cooling, we passed the mixture through a 10 -mm-pore glass filter to separate the sulfuric acid solution from the residue. We measured the concentration of carbohydrate in the filtrate as D-glucose equivalent by the phenol-sulfuric acid method. We estimated the structural carbohydrate content using this carbohydrate concentration. We rinsed the filtered residue with distilled water and dried at $105^{\circ} \mathrm{C}$ for 4 hours. We calculated the lignin content from the weight of the dried residue. Although this fraction included other acid-insoluble (lignin-like) organic components such as secondary compounds and humic substances, this content represents lignin content (Osono and Takeda 2005).

We measured the ash content following the combustion of oven-dried subsamples at $600^{\circ} \mathrm{C}$ for 4 hours. We then dried the remaining portions of the samples at $100^{\circ} \mathrm{C}$ for 3 days to determine the water content and later calculated the content of each constituent per dry matter. A commercial laboratory (Nihon Hakko Shiryo K. K., Kawasaki, Japan) analyzed the crude fat content using the diethyl ether extraction method. Because the remaining amounts of samples of 2 items (mature leaf of sasanqua [Camellia sasanqua] in plot 36 in winter 2006 and litter of long-leaved laurel [Litsea acuminata] in plot 58 in summer 2006) were not sufficient for fat analysis, we assigned these samples the same fat contents as we obtained for those items for the same season in 2005.

We determined contents (\% dry matter) of 8 key constituents in 59 of 62 food items and 157 of 171 other available items at 59 feeding plots (Table S1). We averaged the contents of each constituent in the same plant items in the same seasons of the same years and assigned the average to the items at the feeding plots for each season of the same year (Table S2, available online in Supporting Information).

\section{Statistical Analyses}

We performed statistical analyses using the R statistical computing environment, version 3.2.0 (www.r-project.org, accessed 22 Apr 2015). We first checked for multicollinearity among the explanatory variables (contents of 8 key plant constituents) by calculating the variance inflation factors (VIF) and correlation coefficients $(r)$ among the variables. This confirmed that the VIF of each variable was $<3.0$ and the absolute value of $r$ for any pair of variables was $<0.6$, indicating that multicollinearity in this dataset was acceptable for further analysis (Sergent et al. 1995, Dormann et al. 2013). We then analyzed which constituents were positively and negatively associated with the selection of food items by deer from available items at the feeding plots using generalized linear mixed models (GLMMs), using the glmmadmb function in the glmmADMB package (glmmadmb.r-forge.r-project.org, accessed 24 May 2015).

Initially, we evaluated the association of each key constituent and food selection separately 
using univariate analysis. We set food items (1) or other available items (0) at a given feeding plot as the response variable $(n=233)$ and the content of 1 of the 8 key constituents as the explanatory variable. Because we recorded some items at multiple feeding plots in various seasons, we set feeding plot and season as random effect terms on the intercept in the GLMM (we did not account for sampling year). In addition, we also set focal deer identity (ID) as a random effect term to control for individual differences. We treated the response variable as a binomial distribution and used a logit link function in the GLMM. We repeated this procedure for each key constituent. To test the significance of each model against the null model, we performed a likelihood ratio test using the anova function in the glmmADMB package.

Next, we controlled for the influence of other key constituents (covariates) in each item ( $n=233$ ) at the feeding plots on food selection by including all the key constituents as explanatory variables in the GLMM (multivariate analysis) and running models with all possible combinations of these variables (giving 256 models including a null model). Again, we treated the response variable as a binomial distribution, and set feeding plot, season, and deer ID as random effect terms in the GLMM. Then, we calculated Akaike's Information Criterion (AIC) values for each model, and identified a 95\% confidence set of models by cumulatively summing the Akaike weights from highest to lowest until $\geq 0.95$ (Burnham and Anderson 2002) using the model.sel and model.avg functions in the MuMIn package of R. We then calculated confidence intervals for each model-averaged coefficient of each variable using unconditional standard errors of the coefficient. We excluded variables for which the $85 \%$ confidence intervals of the coefficients included 0 and considered them uninformative variables (Arnold 2010). We then redeveloped the models with all possible combinations of variables excluding the uninformative variables. We calculated the Akaike weights to know the relative importance of each model and selected the models with $\triangle \mathrm{AIC}$ (AIC difference from the best model) $<2.0$. We then used a likelihood ratio test to determine the significance of the selected models against the null model.

\section{RESULTS}

Mean observation time in each observation session (excluding intermittent time when deer behavior was not visible) was 7.5 hours (range $=0.6-23.9 \mathrm{hrs}$ ); the mean total observation time was 91.6 hours (range $=43.7-129.6 \mathrm{hrs}$ ) per season, and 61.0 hours (range $=4.6-183.3 \mathrm{hrs}$ ) per focal animal. Although we could not identify all plant species eaten by focal animals during behavioral sampling, we identified 59 feeding plots in which focal deer fed on 62 food items (Table S1). Eighty-two percent (51 of 62 items) of these food items were fallen parts from woody species (new leaves, mature leaves, bracts, flowers, fruits, seeds, and rotten bark), 13\% (8 items) were living parts from woody species (new leaves, mature leaves, flowers, and bark), and 5\% (3 items) were living herbaceous plants (monocots, dicots, and ferns). These percentages are similar to the annual diet composition that has previously been reported for these deer, expressed as mean percentage of time spent feeding on each food item in 4 seasons 
(fallen parts from woody species: $73 \%$; intact parts from woody species: $13 \%$; intact herbaceous plants: $5 \%$ : spring, $n=2,657$; summer, $n=1,397$; autumn, $n=1,220$; winter, $n=1,131$ ), although the percentage of fallen woody reproductive parts in this study (flowers, fruits, and seeds, 42\%) was higher than in the annual diet (18\%; Agetsuma et al. 2011). Thus, the identified feeding plots were considered representative for analyzing food selection by deer in the study area.

In total, we evaluated the contents of 8 key plant constituents in 62 food items selected by focal deer (40 plant species and plant parts across all observation periods) and 171 other available but not selected items (50 species and parts) at 59 feeding plots (Table S1). There was extensive overlap in the constituent contents of the food items and other available items (Fig. 2).
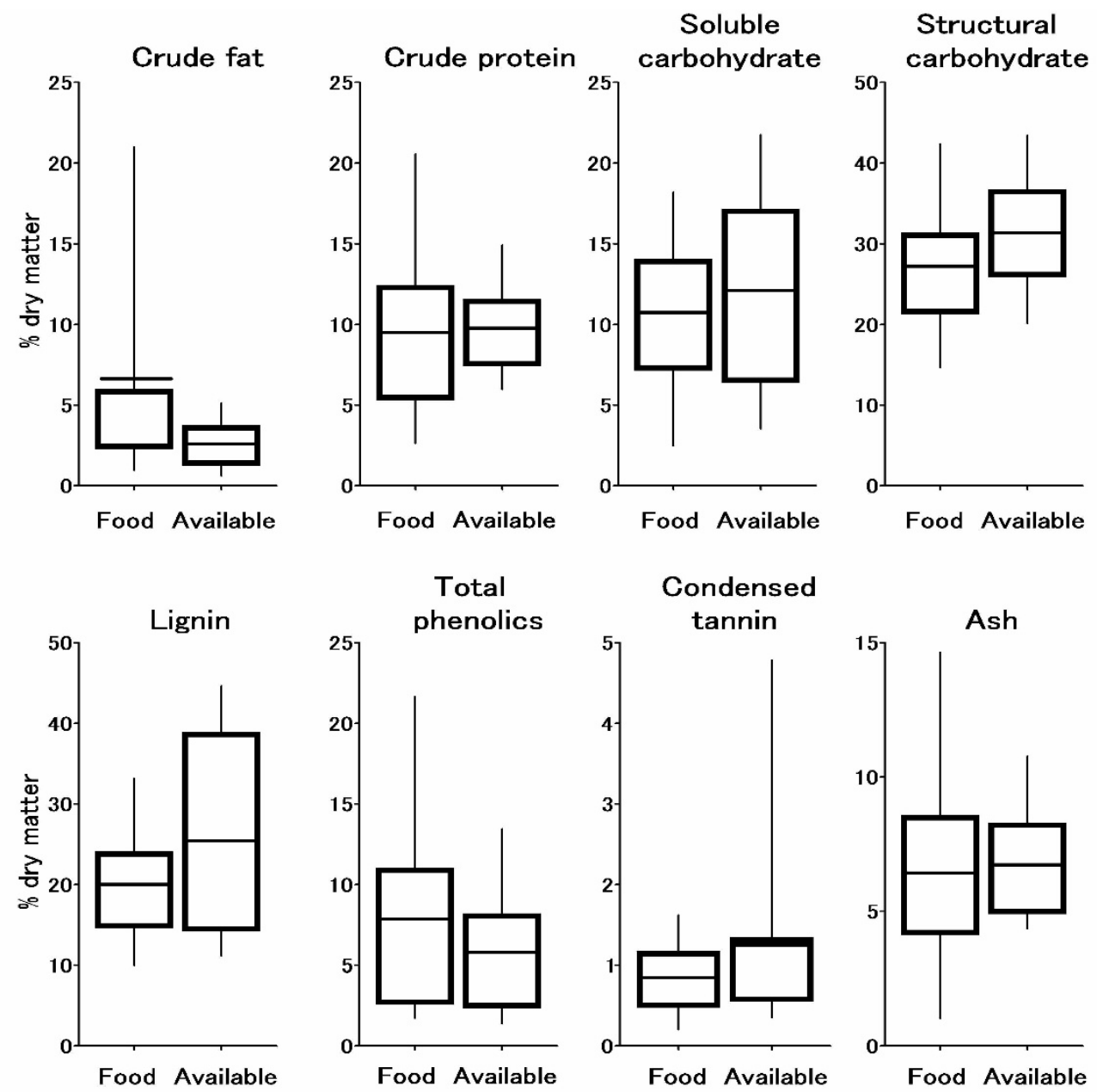

\section{Figure 2}

Box plot of the mean contents (\% dry matter) of 8 key constituents in food items selected by Yaku sika deer (food, $n=62$ ) and other available (uneaten) items (available, $n=171$ ) at 59 feeding plots across 4 seasons in a warm temperate evergreen broad-leaved forest on Yakushima, southern Japan, 2005-2006. In each box plot, the horizontal lines indicate the mean values, the boxes represent the 25 th and 75 th percentiles, and the whiskers represent 
Univariate GLMMs that included crude fat, structural carbohydrate, lignin, total phenolics, or condensed tannin as explanatory variables were significantly different from a null model (likelihood ratio test, $P<0.01$, Table 1). In these models, the crude fat and total phenolics coefficients were significantly positive, whereas the structural carbohydrate, lignin, and condensed tannin coefficients were significantly negative. By contrast, models that included crude protein, soluble carbohydrate, and ash were not statistically different from the null model.

\section{Table 1}

Coefficients from univariate generalized linear mixed models (GLMM) examining which key plant constituents affected food selection at natural feeding plots by wild Yaku sika deer inhabiting a warm temperate evergreen broad-leaved forest on Yakushima, southern Japan, 2005-2006. Each constituent was included separately in each model.

\begin{tabular}{llcc} 
Variable in model & $n^{\mathrm{a}}$ & Coefficient & Likelihood ratio test $(P)$ \\
\hline Crude fat & 233 & 0.278 & $<0.001$ \\
Crude protein & 233 & -0.027 & 0.476 \\
Soluble carbohydrate & 233 & -0.030 & 0.248 \\
Structural carbohydrate & 233 & -0.061 & 0.001 \\
Lignin & 233 & -0.045 & 0.001 \\
Total phenolics & 233 & 0.077 & 0.005 \\
Condensed tannin & 233 & -0.580 & 0.001 \\
Ash & 233 & -0.042 & 0.422 \\
\hline
\end{tabular}

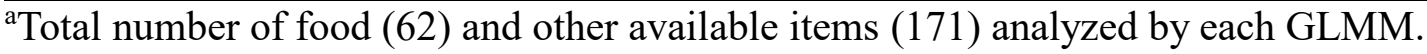

\section{Table 2}

Coefficients from multivariate generalized linear mixed model (GLMM) examining which key plant constituents affected food selection at natural feeding plots by wild Yaku sika deer inhabiting a warm temperate evergreen broad-leaved forest on Yakushima, southern Japan, 2005-2006. We used 233 items (62 food items and 171 other available items) for the GLMM. We selected the model from a set of multivariate generalized linear mixed models using possible combinations of variables after excluding uninformative variables by referring to unconditional standard errors of coefficients of 8 variables in a $95 \%$ confidence set of models.

\begin{tabular}{lcc} 
Variable in selected model & Coefficient & $P$ \\
\hline Crude fat & 0.603 & $<0.001$ \\
Crude protein & 0.127 & 0.004 \\
Lignin & -0.052 & 0.016 \\
Total phenolics & 0.194 & 0.001 \\
Condensed tannin & -0.726 & 0.036 \\
\hline
\end{tabular}

Next, we included all key constituents in the GLMM to control influences of other constituents in each available item. We identified soluble carbohydrate, structural carbohydrate, and ash as uninformative variables. Hence, we analyzed all 32 models that did 
not contain any of the uninformative variables. Only 1 model had $\Delta \mathrm{AIC}<2.0$, which was significantly different from the null model $(P<0.001)$, and its Akaike weight was 0.793 among the 32 models. The selected model contained crude fat, crude protein, and total phenolics as significant positive factors, and lignin and condensed tannin as significant negative factors in the food selection of deer (Table 2).

\section{DISCUSSION}

\section{Effects of Key Plant Constituents on Food Selection}

As we predicted, crude fat and crude protein content of plants had positive effects on food selection by wild Yaku sika deer, whereas lignin and condensed tannin content had negative effects when the influences of other constituents were controlled for in multivariate analysis (Table 2). Conversely, soluble carbohydrate and structural carbohydrate content showed no apparent effects on food selection, and unexpectedly the total phenolics content had a positive effect.

Both crude fat and soluble carbohydrate contribute to the energy intake of animals. However, fat has more energy per unit dry weight than carbohydrates such as sugar and starch (National Research Council 1989, Leeson and Summers 2001), which may make it a particularly desirable nutrient for small-bodied ungulates with short gastrointestinal tracts such as the deer examined in this study (ca. 20-30 kg body weight). This demonstrates that although energy is generally recognized as important in food selection (Robbins 1993), we also need to pay attention to the sources of energy (i.e., fat, sugar, and protein). Relatively few studies have analyzed the fat content of ungulate food plants to date (Deguchi et al. 2001, Ceacero et al. 2012), perhaps because most previous works have been conducted in areas where forage plants are typically low in crude fat. However, ungulates living in warmer habitats consume more fruits and seeds (Gayot et al. 2004, Soumya et al. 2010, Agetsuma et al. 2011), which may have high fat content. A more comprehensive understanding of food selection by ungulates may require more information on the role of fat content in their food items.

Several non-tannin phenolics may be toxic to animals if ingested in large quantities, and ungulates generally trade off digestible matter against non-tannin phenolics when they select food items (Hanley 1997). Although condensed tannin content had a negative effect on food selection by deer, total phenolics content, which includes condensed tannin, had a significant positive effect (Table 2). Tixier et al. (1997) reported that roe deer (Capreolus capreolus) proactively ingest phenolics and speculated that they have developed physiological mechanisms to detoxify phenolics to reduce feeding competition with sympatric red deer (Cervus elaphus). Although the sika deer investigated in this study had no major interspecific competitor, they may experience high intraspecific feeding competition due to their high population density (Agetsuma et al. 2003, Koda et al. 2011). The body size of Yaku sika deer is considerably smaller than other subspecies of Japanese sika deer (e.g., Kyushu sika deer [ $C$. 
n. nippon], Honshu sika deer [C. n. centralis], Ezo sika deer [C. n. yesoensis]; Whitehead 1993). Terada (2012) showed that the dwarfing of Yaku sika deer was genetically linked, potentially because of food limitation from high population density through predator release (Kay 1998, Lomolino 2005). Under these food limitation conditions, deer may have evolved the ability to detoxify phenolics to expand the range of foods they can consume. In addition, this ability may provide a selective advantage for ungulates that show boom-bust population cycles (Hebblewhite et al. 2006, Bradley and Neufeld 2012) during periods of food shortage at high population densities. Alternatively, ungulates may proactively feed on food items containing phenolics (Tixier et al. 1997) because of their various health-promoting effects, such as antioxidant properties (Hollman and Katan 1997, Riihimäki et al. 2008). Further study is required to better understand any potential benefits for ungulates of consuming non-tannin phenolics.

\section{The Importance of Considering Co-Variation between Plant Constituents}

Because multicollinearity among the contents of the 8 key plant constituents was low (VIF $<3.0$ and $|r|<0.6$; Sergent et al. 1995, Dormann et al. 2013), our multivariate analysis could correct the effect of each plant constituent on food selection by deer by controlling the influences of other constituents (i.e., covariates) in each potential food item. We compared the results of univariate (Table 1) and multivariate analyses (Table 2) for evaluating the effects of each constituent on food selection by deer and found 2 main inconsistencies between the procedures. First, crude protein content had a significant positive coefficient in the multivariate analysis (Table 2), whereas the coefficient was not significant in the univariate analysis (Table 1). One explanation for this is that the effect of crude protein relates to food conditions of their habitats. It has previously been estimated that several deer species have protein requirements of $4-10 \%$ in food items for body maintenance (Berteaux et al. 1998). Because the mean crude protein content of food items in our study fell within this range (Fig. 2), it may not have had a major influence on food selection in our study. Rather, it may be that our study deer obtained sufficient protein to meet their daily requirements from a limited number of protein-rich food items and then sought other food items that were high in other favorable constituents, such as fat, but had more modest protein content. This may be relevant for other ungulate diet studies reporting that crude protein contents of frequently eaten food items were similar to or even significantly lower than those of less frequently eaten items under some conditions using univariate analyses (e.g., Vourc'h et al. 2002, Verheyden-Tixier et al. 2008, Zweifel-Schielly et al. 2012). It is possible that positive associations of protein content with food selection might have been detected if they had used multivariate analyses, as in our study.

The second difference we detected was in the effect of the structural carbohydrate content, which had a significant negative coefficient in the univariate analysis (Table 1) but had no detectable effect in the multivariate analysis (Table 2). It may be difficult to judge whether the 
structural carbohydrate caused any negative effect under stronger influences of other constituents. Nonetheless, the effect of the structural carbohydrate was overestimated in the univariate analysis in this study. Applying univariate analyses for many types of plant constituents causes multiple comparison problems that may lead to the Type I errors. Thus, we suggest that statistical procedures, such as univariate analysis, which cannot control the influence of other plant constituents, require careful attention to minimize biases in studies of food selection.

\section{MANAGEMENT IMPLICATIONS}

Our results suggest that some plant constituents that have generally been thought to have negative effects on food selection by ungulates may actually have only little association (structural carbohydrate) or even positive association (plant secondary metabolites) with food selection (Table 2). Therefore, for evaluating qualities of food items for subject species, we should confirm the species-specific negative or positive effects of each plant constituent. In addition, direct observations of the feeding behavior of wild animals under natural conditions can be important for understanding their food selection. This is especially true for ungulates that frequently forage on fallen plant parts where other methods may be biased in detecting these food items.

\section{ACKNOWLEDGMENTS}

We are grateful to the Ministry of the Environment, the Yakushima Forest Environment Conservation Center, Kagoshima Prefecture for permitting us to conduct this research. The Primate Research Institute of Kyoto University offered us the use of their facilities in Yakushima. We would like to thank K. Iwagawa and our friends in Yakushima for supporting our fieldwork, K. Ono, H. Asano and S. Yoshida for help in the laboratory, and D. A. Hill and S. K. Windels for helpful comments on the manuscript. This work was supported by the Research Project Evaluation of Sustainable Forest Use Options and their Perspectives of the Research Institute for Humanity and Nature, by the Research Project Conservation and Management Scheme through Long Term Assessment of Natural Ecosystem in the Yakushima World Heritage Area, Southern Japan of The Nature Conservation Society of Japan, by the Cooperation Research Programs of the Primate Research Institute and Wildlife Research Center of Kyoto University, and by JSPS KAKENHI 14704013, 16780107.

\section{LITERATURE CITED}

Agetsuma, N. 1995. Foraging strategies of Yakushima macaques (Macaca fuscata yakui). International Journal of Primatology 16:595-609.

Agetsuma, N., and Y. Agetsuma-Yanagihara. 2018. Regeneration of natural vegetation under high sika deer density after a mudslide in a warm temperate evergreen forest of Yakushima, Japan. Japanese Journal of Conservation Ecology 23:145-153. [In Japanese with English abstract.] 
Agetsuma, N., Y. Agetsuma-Yanagihara, and H. Takafumi. 2005. Ranging patterns of Japanese sika deer in a warm temperate forest of Yakushima. Pages 4-5 in Research Institute for Humanity and Nature, editor. Annual report of "Sustainability and biodiversity assessment on forest utilization options". Research Institute for Humanity and Nature, Kyoto, Japan. [In Japanese.]

Agetsuma, N., Y. Agetsuma-Yanagihara, and H. Takafumi. 2011. Food habits of Japanese deer in an evergreen forest: litter-feeding deer. Mammalian Biology 76:201-207.

Agetsuma, N., and N. Noma. 1995. Rapid shifting of foraging pattern by Yakushima macaques (Macaca fuscata yakui) as a reaction to heavy fruiting of Myrica rubra. International Journal of Primatology 16:247-260.

Agetsuma, N., H. Sugiura, D. A. Hill, Y. Agetsuma-Yanagihara, and T. Tanaka. 2003. Population density and group composition of Japanese sika deer (Cervus nippon yakushimae) in an evergreen broad-leaved forest in Yakushima, southern Japan. Ecological Research 18:475-483.

Alm, U., B. Birgersson, and O. Leimar. 2002. The effect of food quality and relative abundance on food choice in fallow deer. Animal Behaviour 64:439-445.

Altmann, J. 1974. Observational study of behavior: sampling methods. Behaviour 49:227-267.

Arnold, T. W. 2010. Uninformative parameters and model selection using Akaike's Information Criterion. Journal of Wildlife Management 74:1175-1178.

Bee, J. N., A. J. Tanentzap, W. G. Lee, R. B. Lavers, A. F. Mark, J. A. Mills, and D. A. Coomes. 2011. Influence of foliar traits on forage selection by introduced red deer in New Zealand. Basic and Applied Ecology 12:56-63.

Berteaux, D., M. Cr^ete, J. Huot, J. Maltais, and J-P. Ouellet. 1998. Food choice by white-tailed deer in relation to protein and energy content of the diet: a field experiment. Oecologia 115:84-92.

Bradley, M., and L. Neufeld. 2012. Climate and management interact to explain the decline of woodland caribou (Rangifer tarandus caribou) in Jasper National Park. Rangifer 20:183-191.

Burnham, K. P., and D. R. Anderson. 2002. Model selection and multimodel inference: a practical information-theoretic approach. Second edition. Springer, New York, New York, USA.

Ceacero, F., A. J. García, T. Landete-Castillejos, J. Bartošová, L. Bartoš, and L. Gallego. 2012. Benefits for dominant red deer hinds under a competitive feeding system: food access behavior, diet and nutrient selection. PLoS ONE 7:e32780.

Constantinides, M., and J. H. Fownes. 1994. Tissue-to-solvent ratio and other factors affecting determination of soluble polyphenols in tropical leaves. Communications in Soil Science and Plant Analysis 25: 3221-3227.

Deguchi, Y., S. Sato, and K. Sugawara. 2001. Relationship between some chemical components of herbage, dietary preference and fresh herbage intake rate by the Japanese serow. Applied Animal Behaviour Science 73:69-79.

Dormann, C. F., J. Elith, S. Bacher, C. Buchmann, G. Carl, G. Carré, J. R. G. Marquéz, B. Gruber, B. Lafourcade, P. J. Leitão, T. Münkemüller, C. McClean, P. E. Osborne, B. Reineking, B. Schröder, A. K. Skidmore, D. Zurell, and S. Lautenbach. 2013. Collinearity: a review of methods to deal with it and a simulation study evaluating their performance. Ecography 36:27-46. 
Dostaler, S., J-P. Ouellet, J-F. Therrien, and S. D. Côté. 2011. Are feeding preferences of white-tailed deer related to plant constituents? Journal of Wildlife Management 75:913-918.

Dubois, M., K. A. Gilles, J. K. Hamilton, P. A. Rebers, and F. Smith. 1956. Colorimetric method for determination of sugars and related substances. Analytical Chemistry 28:350-356.

Environment Agency. 1984. Nature of Yakushima. The Nature Conservation Society of Japan, Tokyo, Japan. [In Japanese.]

Felton, A. M., A. Felton, D. Raubenheimer, S. J. Simpson, S. J. Krizsan, PO. Hedwall, and C. Stolter. 2016. The nutritional balancing act of a large herbivore: an experiment with captive moose (Alces alces L). PLoS ONE 11:e0150870.

Forsyth, D. M., D. A. Coomes, G. Nugent, and G. M. J. Hall. 2002. Diet and diet preferences of introduced ungulates (Order: Artiodactyla) in New Zealand. New Zealand Journal of Zoology 29:323-343.

Forsyth, D. M., S. J. Richardson, and K. Menchenton. 2005. Foliar fibre predicts diet selection by invasive red deer Cervus elaphus scoticus in a temperate New Zealand forest. Functional Ecology 19:495-504.

Gayot, M., O. Henry, G. Dubost, and D. Sabatier. 2004. Comparative diet of the two forest cervids of the genus Mazama in French Guiana. Journal of Tropical Ecology 20:31-43.

Hanley, T. A. 1997. A nutritional view of understanding and complexity in the problem of diet selection by deer (Cervidae). Oikos 79:209-218.

Hanya, G., M. Kiyono, H. Takafumi, R. Tsujino, and N. Agetsuma. 2007. Mature leaf selection of Japanese macaques: effects of availability and chemical content. Journal of Zoology 273:140-147.

Hebblewhite, M., E. H. Merrill, L. E. Morgantini, C. A. White, J. R. Allen, E. Bruns, L. Thurston, and E. H. Tomas. 2006. Is the migratory behavior of montane elk herds in peril? The case of Alberta's Ya Ha Tinda elk herd. Wildlife Society Bulletin 34:1280-1294.

Hjeljord, O., N. Hövik, and H. B. Pedersen. 1990. Choice of feeding sites by moose during summer, the influence of forest structure and plant phenology. Holarctic Ecology 13:281-292.

Hochman, V., and B. P. Kotler. 2006. Effects of food quality, diet preference and water on patch use by Nubian ibex. Oikos 112:547-554.

Hollman, P. C. H., and M. B. Katan. 1997. Absorption, metabolism and health effects of dietary flavonoids in man. Biomedicine \& Pharmacotherapy 51:305-310.

Huang, Y, L. Wang, D. Wang, Y. Li, and D. G. Alves. 2012. The effect of plant spatial pattern within a patch on foraging selectivity of grazing sheep. Landscape Ecology 27:911-919.

Johnstone, J., D. E. Russell, and B. Griffith. 2002. Variations in plant forage quality in the range of the Porcupine caribou herd. Rangifer 22:83-92.

Joint FAO/IAEA Division of Nuclear Techniques in Food and Agriculture. 2000. Quantification of tannins in tree foliage. FAO/IAEA, Vienna, Austria.

Kay, C. E. 1998. Are ecosystems structured from the top-down or bottom-up: a new look at an old debate. Wildlife Society Bulletin 26:484-498.

Koda, R., N. Agetsuma, Y. Agetsuma-Yanagihara, R. Tsujino, and N. Fujita. 2011. A proposal of the 
method of deer density estimate without fecal decomposition rate: a case study of fecal accumulation rate technique in Japan. Ecological Research 26:227-231.

Leeson, S., and J. D. Summers. 2001. Energy. Pages 34-99 in S. Leeson, and J. D. Summers, editors. Nutrition of the chicken. Fourth edition. University Books, Guelph, Canada.

Lomolino, M. V. 2005. Body size evolution in insular vertebrates: generality of the island rule. Journal of Biogeography 32:1683-1699.

Maruhashi, T. 1981. Activity patterns of a troop of Japanese monkeys (Macaca fuscata yakui) on Yakushima Island, Japan. Primates 22:1-14.

McLachlan-Troup, T. A., C. R. Dickman, and T. R. Grant. 2010. Diet and dietary selectivity of the platypus in relation to season, sex and macroinvertebrate assemblages. Journal of Zoology 280:237-246.

Moser, B., M. Schütz, and K. E. Hindenlang. 2006. Importance of alternative food resources for browsing by roe deer on deciduous trees: the role of food availability and species quality. Forest Ecology and Management 226:248-255.

Munro, R. H. M., S. E. Nielsen, M. H. Price, G. B. Stenhouse, and M. S. Boyce. 2006. Seasonal and diel patterns of grizzly bear diet and activity in west-central Alberta. Journal of Mammalogy $87: 1112-1121$.

Nakagawa, N. 1989. Bioenergetics of Japanese monkeys (Macaca fuscata) on Kinkazan Island during winter. Primates 30:441-460.

National Research Council. 1989. Recommended dietary allowances, Tenth edition. The National Academies Press, Washington, D.C., USA.

Osono, T., and H. Takeda. 2005. Decomposition of organic chemical components in relation to nitrogen dynamics in leaf litter of 14 tree species in a cool temperate forest. Ecological Research $20: 41-49$.

Raubenheimer, D., G. E. Machovsky-Capuska, C. A. Chapman, and J. M. Rothman. 2015. Geometry of nutrition in field studies: an illustration using wild primates. Oecologia 177:223-234.

Riihimäki, L. H., M. J. Vainio, J. M. S. Heikura, K. H. Valkonen, V. T. Virtanen, and P. M. Vuorela. 2008. Binding of phenolic compounds and their derivatives to bovine and reindeer b-Lactoglobulin. Journal of Agricultural and Food Chemistry 56:7721-7729.

Robbins, C. T. 1993. Wildlife feeding and nutrition. Second edition. Academic Press, San Diego, California, USA.

Sergent, M., D. Mathieu, R. Phan-Tan-Luu, and G. Drava. 1995. Correct and incorrect use of multilinear regression. Chemometrics and Intelligent Laboratory 27:153-162.

Simard, M. A., S. D. Côté, R. B. Weladji, and J. Huot. 2008. Feedback effects of chronic browsing on life-history traits of a large herbivore. Journal of Animal Ecology 77:678-686.

Soumya, P., A. Pittet, and R. Sukumar. 2010. Who really ate the fruit? A novel approach to camera trapping for quantifying frugivory by ruminants. Ecological Research 25:225-231.

Tagawa, H. 1980. Vegetation on the western slope of Mt. Kuniwaridake, Yakushima Island. Science Reports of Kagoshima University 29:121-137. [In Japanese.] 
Tagawa, H. 1994. Natural World Heritage, Yakushima. Japan Broadcast Publishing, Tokyo, Japan. [In Japanese.]

Terada, C. 2012. Geographic variations of morphological and genetic features among island populations of the sika deer (Cervus nippon) in southern Japan: ecological and historical nonexchangeability. Dissertation, Hokkaido University, Sapporo, Japan.

Tixier,H., P. Duncan, J. Scehovic, A. Yani,M. Gleizes, and M. Lila. 1997. Food selection by European roe deer (Capreolus capreoh): effects of plant chemistry, and consequences for the nutritional value of their diets. Journal of Zoology 242:229-245.

Tsuji, Y., K. A. Widayati, S. Nila, I. Hadi, B. Suryobroto, and K. Watanabe. 2015. "Deer" friends: feeding associations between colobine monkeys and deer. Journal of Mammalogy 96:1152-1161.

Tsujino, R., and Y. Agetsuma-Yanagihara. 2006. Alien mammals, raccoon dog, feral dog, feral cat, and feral goat in western and north-western part of lowland forest on Yakushima Island in Kagoshima Prefecture. Japanese Journal of Conservation Ecology 11:167-171. [In Japanese.]

Ulappa, A. C., R. G. Kelsey, G. G. Frye, J. L. Rachlow, L. A. Shipley, L. Bond, X. Pu, and J. S. Forbey. 2014. Plant protein and secondary metabolites influence diet selection in a mammalian specialist herbivore. Journal of Mammalogy 95:834-842.

Van der Wal, R., N. Madan, S. van Lieshout, C. Dormann, R. Langvatn, and S. D. Albon. 2000. Trading forage quality for quantity? Plant phenology and patch choice by Svalbard reindeer. Oecologia 123:108-115.

Vangilder, L. D., O. Torgerson, and W. R. Porath. 1982. Factors influencing diet selection by whitetailed deer. Journal of Wildlife Management 46:711-718.

Van Soest, P. J., J. B. Robertson, and B. A. Lewis. 1991. Methods for dietary fiber, neutral detergent fiber, and nonstarch polysaccharides in relation to animal nutrition. Journal of Dairy Science 74: 3583-3597.

Verheyden-Tixier, H., P-C. Renaud, N. Morellet, J. Jamot, J-M. Besle, and B. Dumont. 2008. Selection for nutrients by red deer hinds feeding on a mixed forest edge. Oecologia 156:715-726.

Vourc'h, G., B. Vila, D. Gillon, J. Escarré, F. Guibal, H. Fritz, T. P. Clausen, and J-L. Martin. 2002. Disentangling the causes of damage variation by deer browsing on young Thuja plicata. Oikos 98: $271-283$.

Wam, H. K., and O. Hjeljord. 2010. Moose summer diet from feces and field surveys: a comparative study. Rangeland Ecology and Management 63:387-395.

Whitehead, G. K. 1993. The Whitehead encyclopedia of deer. Swan Hill Press, Shrewsbury, United Kingdom.

Zweifel-Schielly, B., Y. Leuenberger, M. Kreuzer, and W. Suter. 2012. A herbivore's food landscape: seasonal dynamics and nutritional implications of diet selection by a red deer population in contrasting Alpine habitats. Journal of Zoology 286:68-80.

Associate Editor: Steve Windels. 
Table S1

Table S1 Plant species and parts, condition, and abundance of food items and other available items at natural feeding plots used by focal wild Yaku sika deer (Cemuse

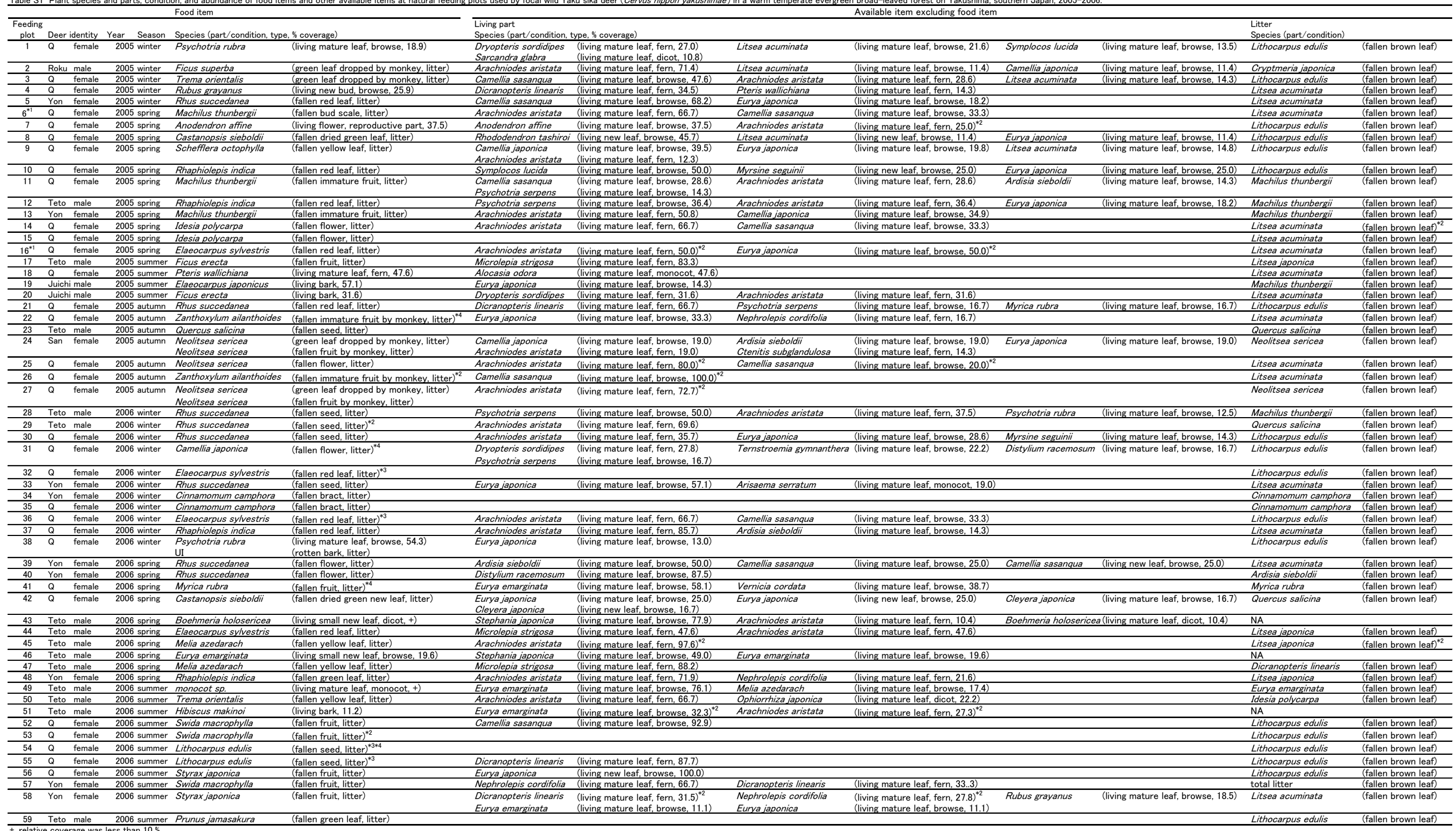

59 Teto male 2006 summer Prunus jamasakura $\quad$ (fallen green leaf, litter)-

+, relative coverage was less than 10,0
NA, not available at the feeding plot.
Ul, species unidentified

*1, feeding plot No.6 and No. 16 were the same location used in different days for different food items in the same season.
$* 2$, sample was not oollected the feeding plot but shared with that collected in neighboring feeding plot within $160 \mathrm{~m}$ in the same season.

$* 3$, sample was combined with that from neighbor feeding plot within $120 m$
$* 4$, sample for fat analysis was collected different place of the feeding plot. 
Table S2

Tabale S2 Contents ( $\%$ dry matter) of 8 key constituents in food items and other available items at natural feeding plots used by focal wild Yaku sika deer (Cervus nippon yakushimae) in a warm temperate evergreen broad-leaved forest on Yakushima, southern Japan, $2005-2006$.

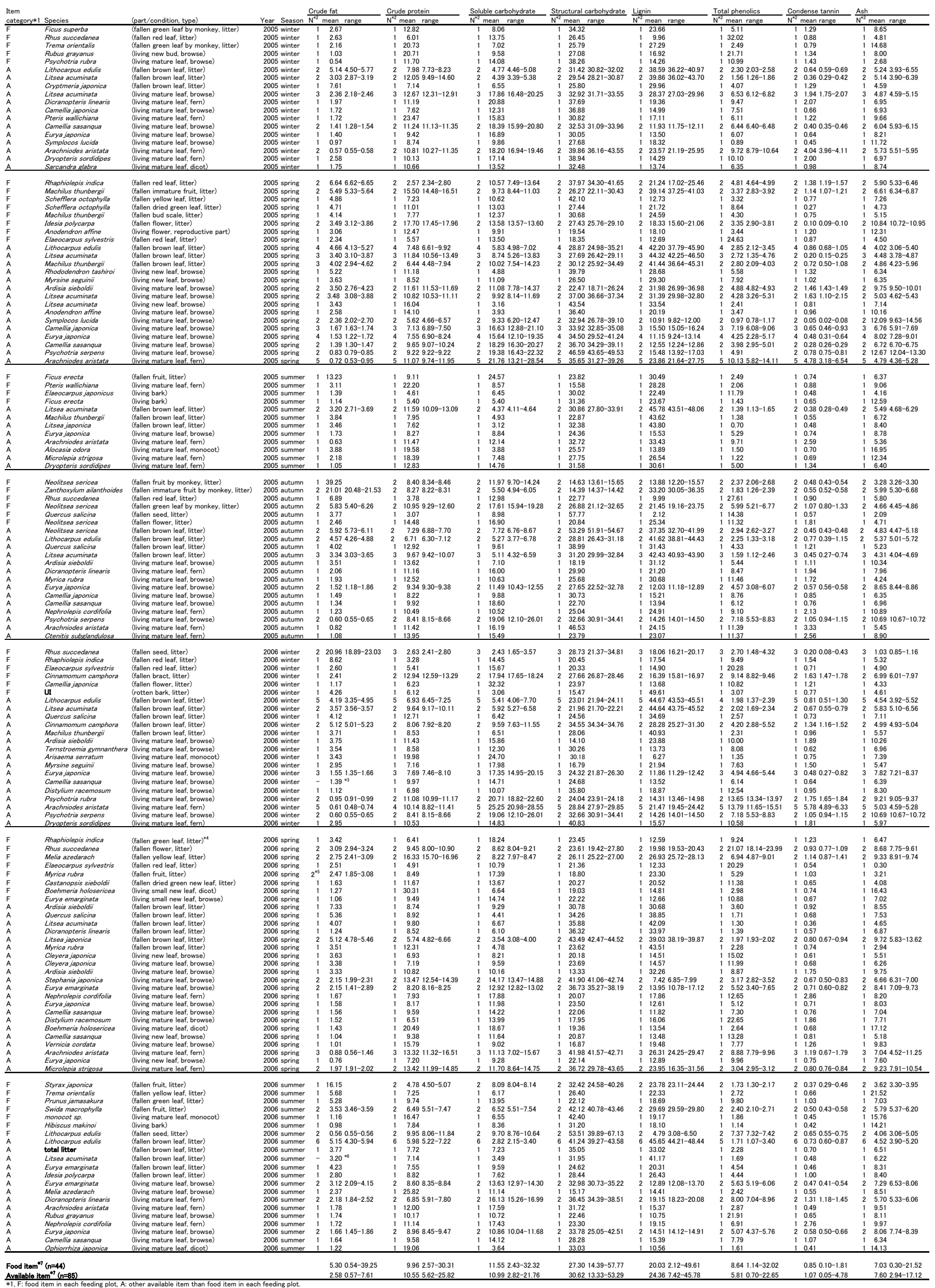

